\title{
QUO VADIS KAJIAN MANUSKRIP JAMBI
}

\author{
Ali Muzakir \\ Universitas Islam Negeri Sulthan Thaha Saifuddin Jambi \\ muzakir_adab@uinjambi.ac.id
}

\begin{abstract}
This paper discusses Jambi's manuscripts and their potential for study. The manuscripts are not huge. The seminal manuscript has produced since the early Jambi Sultanate in the mid-1 $17^{\text {th }}$ century. Using historical and codicology perspective, this writing analyzes the origins, sources and usingthe manuscript. This research presented that Jambi's manuscript was emerging along with the dissemination of Islam. The close link that existed between Palembang and Jambi during sultanate had influenced manuscript production.A number of Palembang manuscripts had influenced Jambi.
\end{abstract}

Keywords: manuscript, Jambi sultanate, writer, copyst

\section{PENDAHULUAN}

Naskah kuno banyak tersebar di seluruh wilayah Indonesia, tersimpan dalam berbagai lembaga pemerintah baik dalam maupun luar negeri dan banyak juga yang masih disimpan oleh masyarakat sendiri. Teks-teks naskah kuno Nusantara pada dasarnya merupakan dokumen tertulis yang merekam suatu kompleks ide atau gagasan masyarakat pada zamannya yang berisikan berbagai aspek kehidupan seperti ajaran keagamaan, ajaran moral, kesusastraan, kebahasaan dan sebagainya (Permadi, 2011:1). Naskah kuno merupakan tulisan orang-orang terdahulu yang sangat penting, karena dari sumber data tertulis ini dapat memberikan kejelasan sejarah dan kebudayaan suatu bangsa yang bermacam-macam jenisnya. Melalui kesaksian tertulis tersebut kita dapat mengetahui dan mempelajari cara berpikir, perasaan dan kebudayaan bangsa yang bersangkutan. Kesaksian tertulis jenis inilah yang disebut sebagai naskah lama atau naskah kuno (Pudjiastuti, 2010:3). Naskah kuno tertulis dalam berbagai aksara dan bahasa, seperti huruf Jawi (huruf Arab) untuk teks bahasa Melayu, Minang dan Ambon, Huruf Buri Wolio (huruf Arab) untuk teks berbahasa Wolio, Huruf Pegon (huruf Arab) untuk teks berbahasa Jawa, Sunda dan Madura, serta banyak lagi aksara dan bahasa lainnya (Mulyadi,1994:6-9). Berdasarkan gaya atau aliran teksnya, naskah-naskah Nusantara meskipun memiliki ciri kedaerahannya, tetapi secara umum isinya dapat dibagi beberapa kategori. Kategori naskah kuno ini seperti teks keagamaan, teks bernuansa sejarah, sastra, bahasa, ajaran moral dan etika, undang-undang dan hukum adat, legenda, folklor, seni (tari, musik, kriya, drama, suara dan batik), teknologi, obat-obatan, ramalan, ilmu tua (mantra, primbon, jimat), permainan, nasihat dan larangan, dan lain sebagainya (Pudjiastuti,2010:10).

Beberapa contoh naskah kuno dalam kategori teks bernuansa sejarah yaitu teks Babad Tanah Jawi, teks bernuansa sastra dan sejarah yaitu Hikayat Raja-Raja Pasai yang dimiliki oleh Provinsi Aceh, Inilah Syajarah Kerajaan Jambi, Hikayat Hang Tuah, Hikayat Sri Rama, Serat Centhini dan lain-lain. Dari naskah ini dapat memberikan informasi tentang sejarah dan keindahan sastra dibeberapa wilayah di 
Nusantara. Adapula naskah yang berisi undang-undang dan hukum adat seperti naskah melayu yang tertua Kitab Undang-Undang Tanjung Tanah berasal dari tanah Kerinci dan Tambo Alam Minangkabau yang dimiliki oleh masyarakat Sumatera Barat.

\section{ADOPSI AKSARA ARAB}

Kedatangan Islam telah meningkatkan kemampuan literasi (baca-tulis) masyarakat di kawasan Melayu.Huruf-huruf Arab yang menyertai penyebaran Islam telah diadopsi dan diadaptasi untuk keperluan penulisan.Huruf-huruf Arabdinilai lebih mudah penggunaannya dibandingkan dengan huruf-huruf warisan dari India, seperti pallawa, kawi, dan kaganga (Molen, Kozok dan Loir, 2009:325). Dalam kajian naskah, penulisan Melayu yang menggunakan aksara Arab disebut jawi.Pada awalnya tradisi tulisan jawi berkembang secara pesat di Aceh pada abad ke-17.Tulisan jawisecara luas digunakan di seluruh kawasan Melayu untuk penulisan karya-karya kesusanteraan, keagamaan, sejarah, politik, perdagangan, pengobatan, perundang-undangan, dan sebagainya.

Tulisan ini fokus pada karya-karya keagamaan yang masih masih berupa manuskrip yang ditemukan di Jambi.Secara sporadis penulisan Jawi mulai digunakan secara sangat terbatas oleh sultan-sultan Jambi pada abad ke-17.Sultan menggunakannya untuk kepentingan politik dan perdagangan.Tradisi menulis manuskrip-manuskrip keislaman dimulai pada awal ke-19, yang terpengaruh manuskrip Palembang.Sejak abad ke-18, Palembang tampil sebagai pusat produksi manuskrip keislaman yang terpenting di Sumatra (Faturrahman, 2006: 383-393). Untuk itu tulisan mengungkap pengaruh manuskrip Palembang terhadap Jambi.

\section{MANUSKRIP KESULTANAN}

Manuskrip Jambi yang paling awal adalah berupa surat-surat di masa kesultanan. Tradisi pernaskahan di Jambi muncul seiring dengan pembentukan Kesultanan Jambi pada awal ke-17. Shellabear adalah orang pertama yang mengungkap keberadaan salah satu suratkPangeran Jambi yang ia temukan di Perpustakaan Universitas Leiden, Belanda. Surat yang ditujukan kepada Johan Maetsuijker Gurnador di Batavia memang tidak memiliki bertanda tahun, tetapi otoritas VOC yang menerimanya sempat membuat disposisi surat tanggal 30 April 1669. Pada pojok kanan atas surat tertulisAl-Khalifah al-Mu 'min Pangeran Jambi Khalid Allah Malkah. Isinya ingin menjalin persahabatan dagang dan membeli persenjataan kepada Belanda (Shellabear, 1898:107- 151). Gallop mengidentifikasi lebih 40 surat sultan-sultan Jambi yang ditulis dalam rentang pertengahan abad ke-17 sampai abad ke-19 (Annabel, 2002: 194-207). Masih di Perpustakaan Universitas Leiden, Kukushkin menganalisis manuskrip Hikayat Negeri Jambi, sebagai sumber sejarah Jambi.Hikayat Negeri Jambi ditulis pada pertengahan abad ke-19 yang merekam cerita lisan dan legenda yang berkembang pada masyarakat Jambi 
Losher-Scholten menduga bahwa istana kesultanan menyimpan banyak manuskrip, sayangnya telah terbakar ketika Belanda menyerang Jambi pada tahun 1858. Manuskrip yang diselamatkan adalahUndang-undang Jambi dan legenda asal-usul keturunan keluarga sultan (Scholten, 2004: 17). ManuskripUndangundang Jambi tersebut telah ditranskripsi ulang dan diterjemahkan ke dalam Bahasa Belanda oleh van den Berg pada tahun 1894.Undang-undang terdiri dari 32 pasal, tentanghukum Adat dan beberapa ketentuan syariah yang diterapkan pada masa kesultanan.Ditulispada tahun 1283/1866 atas perintah Sultan Ahmad Nazhar al-Din (memerintah 1858-1881), sesuai dengan adat yang juga telah berlaku sejak masa Sultan Ahmad Zayn al-Din (1770-1790). Hal ini terbaca di dalam mukadimahnya:

Hijrat al-nabiy shallallah 'alayh wa salam seribu dua ratus delapan puluh tiga tahun kepada tujuh belas hari bulan rabi' al-awal bahwa masa itulah sri paduka maulana al-sulthan Ratu Ahmad Nashr al-Din memerintahkan Ki Demang Setya Wiguna Ja'far memegang bicara adat yang dipegang dipakai seperti zaman syai lillah Sulthan Ahmad Zayn al-Din (Berg: 1894: 127).

Manuskrip kesultanan yang lain adalah Undang-undang Piagam Pecacahan Jambi (ditulis oleh Ngabehi Sutho Dilogo pada tahun 1317/1899) dan Ini Syajarah Kerajaan Jambi (yang juga ditulis oleh Ngabehi Sutho Dilogo, tapi tanpa data tahun). Kedua manuskrip tersebut memuat informasi penting mengenai sejarah Islam, silsilah sultan, pasal-pasal ketentuan adat dan syariat. Silsilah sultan Jambi disebut keturunan dari Putri Selaro Pinang Masak, yang datang dari Pagaruyung, dan kemudian menikah dengan Ahmad Barus II yang berasal dari Istambul, Turki. Manuskrip Ini Syajarah Kerajaan Jambi menyatakan:

Dengan sesungguhnya saya Ngabehi Sutho Dilogo Priyayi Raja Sari, pembesar dari orang Kerajaan Jambi yang Dua Belas Bangsa, menerangkan dari Pasal Keturunan Raja-raja yang ada sekarang ini, serta keturunan orang kerajaan yang dua belas bangsa. Dan tatkala mati Tun Telanai, ini Jambi tidak beraja lagi, maka turun anak raja Pagaruyung ke Jambi, perempuan namo Tuan Putri Selaro Pinang Masak (Foto copy Ms., "Ini Sajarah Kerajaan Jambi:1).

Ahmad Barus II, yang kemudian diberi gelar Datuk Paduka Berhala, digambarkan memiliki genealogi/silsilah sampai kepada keluarga Nabi Muhammad: "Asalnya Datuk Paduka Berhala, raja Turki turunan dari Sulthan Saydina Zayn al-'Abidin bin Saydina Husayn binti Fatimah Zahara binti SaydinaRasul." (Foto copy Ms., "Ini Sajarah Kerajaan Jambi:9). Ahmad Barus II mendakwahkan Islam ke Jambi. Salah seorang anaknya, Orang Kayo Hitam, dipandang sebagai tokoh yang paling berperan dalam penyebaran Islam sampai ke pedalaman Jambi.

Peri menyatakan awal Islam ini Jambi zaman Orang Kayo Hitam bin Datuk Paduka Berhala yang me-Islam-kannya. Kepada Hijrat Nabi shallallah 'alayh wa salam 700 tahun dan kepada tahun Alif bilangan Khamsiah, dan kepada sehari bulan Muharam hari Kamis pada waktu 
zuhur masa itulah awal Islam ini Jambi mengucap dua kalimah syahadat, sembahyang lima waktu, puasa sebulan Ramadhan, dan zakat fitrah. Baharulah berdiri rukun Islam yang lima (Foto copy Ms., "Ini Sajarah Kerajaan Jambi:41).

Kisah-kisahkonversi Islam yang ditandai dengan kedatangan seorang Muslim dari Arab, Persia, dan Turki adalah tipikal historiografi tradisional di kawasan Melayu (Jones, 1979:129). Tambo Minangkabaumengisahkan kejadian Alam Minangkabau bersamaan dengan dua alam lain, yaitu "Benua Ruhum" (Turki Utsmani) sebagai penguasa wilayah Barat dan "Benua Cina" sebagai penguasa wilayah Timur. Historiografimuslim Gayo Aceh juga menyeritakan setelah terbentuk Sumatera, "Penguasa Rum" datang ke Aceh. Beberapa kesultanan Nusantara sengaja membangun kesadaran politik bagian dari Dar alIslamyang berpusat Timur Tengah dan Turki Utsmani.Abad ke-16 sampai ke-19 Turki Utsmani adalah patron terpentingdunia Islamdari teror bangsa-bangsa Eropa. Dalam konteks inilah,Undang-undang Piagam Pecacahan Jambi dan Ini Syajarah Kerajaan Jambi mengaitkansejarah Jambi denganTurki. Faktanya, Thaha Sayf al-Din (w. 1322/1904), dalam upayannya melawan Belanda,beberapa kali mengirim suratpolitik ke Turki.

\section{MANUSKRIP KEAGAMAAN}

Agak berbeda dengan manuskrip kesultanan, yang isinya mengenai sejarah, politik, dan otoritas sultan, manuskrip keagamaan memuat ajaran-ajaran Islam seperti aqidah, fiqih, tasawuf, do'a, dan al-Qur'an.Secara umum, produksi manuskrip keagamaan di Jambi tidak terlalu banyak jika dibandingkan dengan tetangganya yang terdekat,khususnya Palembang dan Minangkabau. Perkembangan manuskrip keagamaan Jambi dipengaruhi oleh manuskrip Palembang(Muzakkir, 2012:217-238). Beberapa manuskrip Palembang tersebar ke Jambi dan secara sengaja disalin oleh ulama-ulama Jambi. Pengaruh dan penyebaran manuskrip keagamaan dari satu daerah ke daerah yang lain adalah bagian diseminasi ajaran-ajaran Islam di Kawasan Melayu (Faturrahman, 2009:1048).

Saat ini, jika ingin melihat koleksi terbesar manuskrip keagamaan Jambi berada di Museum Si Ginjai.Menurut catatan Buku Inventaris Koleksi Filologika Museum Negeri Jambi, ada 88 manuskrip.Tampaknya, jumlah tersebut harus direvisi karena beberapa koleksinya tidak ditemukan lagi dan tentunya juga ada penambahan koleksi terbaru.Kampung Pecinan (Seberang Kota Jambi) merupakan kantong terpenting sumber manuskrip di Jambi.Bahkan, beberapa masyarakat masih menyimpan manuskrip sebagai warisan suci keluarga.Di kawasan Seberang Kota Jambi, misalnya, Majid al-Ghaffar (w. 1984) memiliki 4 manuskrip, Guru Tarmizi (w. 2017) menyimpan 4 manuskrip, Aulia Rahman paling sedikit menyimpan 8 manuskrip, dan Ust.Edi menyimpan 10 manuskrip.Selain itu, di Desa Lubuk Resam Kecamatan Cermin Nan Gedang Sarolangun, Bapak Kistolani menyimpan 8 manuskrip.Beberapa manuskrip lainnya dalam jumlah kecil juga 
ditemukan di Desa Tanjung (Sarolangun), Kumpeh (Muaro Jambi), Pulau Rengas dan Jangkat (Merangin).

\section{Penulis dan Penyalin Manuskrip}

Di bawah ini akan disajikan beberapa karya ulama Jambi, yang ditulis dalam rentang awal pada abad ke-19 sampai abad ke-20.

1.1 Manuskrip paling tua: Qurrat al-'Ayn li Fardh al-'Ayn

Sejauh penelusuran, Qurrat al-'Ayn li Fardh al-'Ayn adalah manuskrip keagamaan yang paling awal di Jambi yang ditulis tahun 1232/1817. Satu manuskrip disimpan di museum (Arsip Museum Siginjai) dan dua lainnya dimiliki oleh Ust. Edi. Penulisnya teridentifikasi di dalam kolofon:

Bermula telah selesailah daripada menghimpun risalah ini pada hari itsnayn24 hari bulan Muharram pada tarikh 1232.Al-jami' huwa al-faqir Muhammad Zayn ibn al-haj 'Abd al-Ra'uf al-Jambi al-Syafi'i al-Asy'ari al-Naqsyabandi.... Dan kami namai ia akan risalah Qurrat al-'Ayn li Fardh al- 'Ayn, artinya tatap mata hati bagi menyatakan segala fardhu 'ayn (Ms., Qurrat al-'Ayn, h. 46.).

Penulis oleh Muhammad Zayn al-Jambi pada 24 Muharam 1232/1817.Tidak banyak informasi tentang dirinya. Latar belakang ayahnya yang telah menunaikan ibadah haji pada awal abad ke-19 menunjukkan bahwaia berasal dari keluarga yang religius.Iabermazhab fiqh Syafi'iyah, kalam Ash'ariyah, dan Tarekat Naqsyabandiyah.Qurrat al-'Ayn li Fardh al-'Ayn memiliki hubungan dengan ulama Palembang, bernama Muhammad Hasyim yang menyalinnya tahun 1301/1883. Kolofon manuskrip menyebutkan:

Telah khatam menyurat kitab ini kepada tangan faqir yang hina haji Muhammad Hasyim bin haji 'Abd al-Rahman al-marhum kepada tarikhnya seribu tiga ratus lebih satu tahun kepada empat

likur hari bulan Muharram hari sabtu

$$
\begin{gathered}
\text {...... Siti Hajir istri } \\
\text { Hanafi bin haji } \\
\text { Qasim Palembang } \\
\text { adanya }
\end{gathered}
$$

Tammat Sanah 1301(Ms., Qurrat al-'Ayn, h. 46.)

\section{Abu Bakar Pecinan: Penyalin Manuskrip paling Produktif}

Abu Bakr Pecinanadalah penyalin manuskrip yang produktif.Ia menyalin Jawharat al-Tawhid tahun 1290/1873, Tanbih al-Ghafilin juga tahun 1290/1873, dan Mukhtashar pada tahun 1301/1884. Belum banyak diperoleh informasi mengenai asal-usuk Jawharat al-Tawhid. Kemungkinan terkait dengan karya Syihab al-Din tahun 1162/1748 di Palembang.Karya Syihab al-Din ini adalah terjemahan Bahasa Melayu dari Jawharat al-Tawhid-nyaBurhan al-Din Ibrahim bin al-Laqqani(w. 1022/1631).

Manuskrip Tanbih al-Ghafilinditemukan di rumah 'Abd al-Majid Ghaffar, Kampung Jelmu. Pada halaman sampulnya tertulis: "Ada pun yang impunya ini 
kitab al-haj Abu Bakr bin Tajwal ibn al-marum Pecinan, Kampung Tengah, adanya." Kolofon manuskrip menyebut bahwa Abu Bakar Pecinan menulisnya pada tahun 1290/1873.

Ada pun yang empunya surat serta menyuratnya Tanbih al-Ghafilin ini alhajj Abu Bakr binti al-marhum Tawal adanya. Tammat yawm al-jum'ah waqt al-'ashr tsamaniyah wa 'isyrin, dzul al-safar min hijrah sayd almursalin, 1290. Adapun yang empunya akan dia al-haj Abu Bakr binti almarhum tajwal (Ms., Tanbih al-Ghafilin, h. 62.)

Jawharat al-Tawhidterdiri dari 36 halamanyang ditulis dalam bentuk nazham144 bait.Teks ditulis dalam Bahasa Arab, dan diberi terjemahan gantung dalam Bahasa Melayu dengan aksara Jawi. Isinya mengajarkan pokok-pokok keimanan, sifat-sifat wajib, jaiz, dan mustahil pada Tuhan. Kolofonnya menyebutkan:

Sudah menyurat nazham Jawharat al-Tawhid pada hari sabtu pada awal zuhur waktu jam pukul satu siang pada tarikh sanah 1290 tahun Nabi dan menyuratnya hamba al-Haj Abu Bakr, serta punya ini surat, bin Tajwal ibn al-marhum

Pecinan, Kampung Tengah, Masjid Baru,

Adanya (Ms., Tanbih al-Ghafilin, h. 29.)

Mukhtashar sejatinya adalah karya ulama Palembang, Kemas Fakhr alDin, yang diperkirakan hidup antara tahun 1719/1133 sampai 1763/1177 (Azra, 1994: 245). Mukhtashar ditulis pada tahun 1208(1793). Hampir seratus tahun kemudian, Abu Bakar Pecinan menyalinnya pada tahun 1301/1884. Dalam kolofon manuskrip Abu Bakar Pecinan menyatakan:

Wakitabuha Abu Bakr Ibn Tajwal ibn al-Marhum Bilad al-Jambi Kampung Tengah Masjid Baru. Syahdan, yang empunya kitab Fath alRahman ini hamba al-Haj Abu Bakr Pecinan. Syahdan, telah selesailah Haji Abu Bakr menyurat pada tiga puluh hari bulan Rabb al-Akhir, hari Rabi' malamnya, waktu jam pukul satu malam adanya, pada Hijrah seribu tiga ratus satu tahun pada bilangan arba'iyah 1301 .

Meskipun produktif menyalin manuskrip, tidak diperoleh informasi mengenai riwayat hidup Abu Bakar Pecinan.Jika dilihat dari rentang waktu penyalinan, antara tahun 1290/1873 sampai tahun 1301/1884,AbuBakr Pecinan kemungkinan masih hidup menjelang akhir abad ke-19.

Pecinan beberapa kali muncul di dalam manuskrip-manuskrip Jambi. Selain Abu Bakar Pecinan, nama lain yang mengasosiasikan diri dengan Pecinan adalah Muhammad Hasyim yang menulis Muqaddimat al-Mubtadin. Manuskrip ini adalah koleksi ust.Edi. Pada kolofonnya tertulis:

Sudah daripada menyurat muqadimah ini kepada 24 bulan Zulqaidah yawm al-rabi' waktu 'ashr kepada tarikh sanah 1282 di dalam negeri Jambi tanah Pecinan. Wa katibih al-hajj Muhammad Hasyim ibn al- 
marhum al-hajj 'Abd al-Rahman wa shahibih Muhammad ibn al-hajj Syams al-Din ibn al-hajj Labay fi al-Jambi Pecinan adanya.

Muhammad Hasyim bin 'Abd al-Rahman belum pernah disinggung sama sekali dalam sejarah ulama Jambi. Muqaddimat al-Mubtadin yang ditulisnya selesai pada tahun 1282/1865.

\section{Manuskrip Catatan Harian Ulama Keturunan Palembang}

Manuskrip dari Palembang sangat mempengaruhi perkembangan manuskrip di Jambi.Pada abad ke-18, Kesultanan Palembang adalah pusat terpenting tradisi manuskrip di Sumatra (Pudjiastuti, 2006:383-393). Salah satu ulama yang paling berpengauh adalah Abd al-Shamad al-Palimbani (w. 1203/1789).Magnum opus-nya ialah Hidayat al-Salikin fi Suluk Masalik alMuttaqin (ditulis tahun 1195/1781) dan Sayr al-Salikin ila 'Ibadat Rabb al'Alamin.Satu salinan naskah Hidayat al-Salikin fi Suluk Masalik al-Muttaqin ditemukan di Jambi.Versi cetakannya dibaca di madrasah-madrasah tradisional di Jambi.

Tidak hanya penyebaran manuskrip, beberapa keturunan ulama Palembang juga muncul dan berkarya di Jambi. Salah satunya adalah Abd al-Majid Ghaffar. Majid al-Ghaffar memiliki manuskrip yang mencatat peristiwa-peristiwa penting di dalam keluarganya, seperti silsilah, kelahiran, dan kematian. Di dalam manuskripnya,ia menyebut asal-usul keluarganya:

Ayahanda Haji 'Abd al-Ghaffar bin guru haji 'Abd al-Ghani bin guru haji 'Abd al-Wahid bin haji Qadr al-Din bin haji Badr al-Din; buyut haji 'Abd al-Wahid berasal dari Palembang Kampung 14 Ilir Sungai Rindang.

Nama penting dalam silsilah tersebut adalah kakeknya, 'Abd al-Wahid bin haji Qadr al-Din bin haji Badr al-Din.Abd al-Wahid Palembang memiliki satu karya yang berjudul Fa`idh al-Ilahi, yang ditulis di Mekkah tahun 1282 /1866.Fa idh al-Ilahi belum diinventaris dalam katalog naskah. Satu salinannya ditemukan di Palembang dan dua di Jambi.Fa idh al-Ilahi adalah panduan bay'at, zikir, adab, dan silsilah spiritual pengikut Tarekat Qadiriyah wa Naqsyabandiyah. Abd al-Wahid Palembang menyebut dirinya khalifah Ahmad Khatib Sambas, pendiri tarekat tersebut (Muzakkir, 2014).

Belum ditemukan informasi, kapan keluarga Majid al-Ghaffar datang ke Jambi.Majid al-Ghaffar pernah menelusuri silsilah keluarganya ke Palembang.Ia telah mengunjungi anak dari saudara buyutnya, haji 'Abd al-Wahid, di Kampung 4 Ulu Palembang pada tahun 1935 dan 1936.Pada catatan lain, iamenyebut bahwa latar belakang keluarganya adalah ulama yang perpengaruh di masa kesultanan dan buyutnya bergelar "qadhi" dan "Guru Alam".

Ayahanda Haji "Abd al-Ghaffar bin datuk nda qadhi guru haji 'Abd al-

Ghani bin haji 'Abd al-Wahid bergelar "Guru Alam" pada masa sultan sebelum penjajah Belanda.

Abd Majid al-Ghaffar telah menghasilkan tiga belas karya yang telah diterbitkan.Di dalam karyanya, Majid al-Ghaffar menulis namanya 'Abd al-Majid 
bin Haji 'Abd al-Ghaffar al-Sumathri al-Jambi Al-Pasyinani. Di kalangan masyarakat Jambi, ia popular dipanggil Majid al-Ghaffar. Namun sayangnya, hanya dua karya yang sempat disimpan oleh keturunannya, yaitu Syams alHidayah fi Qishshah Mawlud al-Nabiy Khayr al-Bariyyah dan Hasyiyah Anwar Tijan al-Dirariy 'ala Matan al-Bajuriy.Hasyiyah Anwar tidak berbentuk terbitan tetapi masih berupa manuskrip yang ditulis pada kertas double folio. Selain itu, Majid al-Ghaffar, semasa hidupnya, memiliki tiga manuskrip, yang berjudul Kitab Sembahyang, Bahwa Majid al-Ghaffar telah melahirkan tiga belas karya terbaca pada halaman akhir Syams al-Hidayah, yang pada sampul belakangnya menginformasikan Percetakan Alma'arif Bandung. Ketiga belas karya tersebut adalah Bahjat al-Bidayah fi al-Masa il al-Khilafiyyah $(1353 \mathrm{H})$, Manhaj alGhulam ila Ma'rifat Arkan al-Iman wa al-Islam (1354), Hasyiyah Anwar Tijan al-Dirariy 'ala Matan al-Bajuriy (1354), Syarh Bulugh al-Raja 'ala Safinat alNija (1355), Miftah al-Lisan fi Tazkirat al-Ikhwan (1356), Al-Injad fi al-Wa'zh wa al-Irsyad (1357), Al-Jawahir al-Sunniyah fi al-Khithab wa al-Ada'iyyah (1358), Syams al-Hidayah fi Qishshah Mawlud al-Nabiy Khayr al-Bariyyah (1359), Hasyiyah Badr al-Duja 'ala Bulugh al-Raja (1359), Al-Quthuf al-Daniyyah fi alAhadits al-Nabiwiyyah (1370), Jadwal al-Fara id (1370), dan Hidayat al-Shibyan fi al- 'Aqa id wa al-Shalah wa Tajwid al-Qur'an (1372).Tipikal karya-karya Majid al-Ghaffar adalah judulnya ditulis dalam Bahasa Arab, tetapi isinya dalam Bahasa Melayu (jawi).

\section{KESIMPULAN}

Jambi memiliki khazanah manuskrip yang ditulis sejak masa kesultanan.Manuskrip-manuskrip kesultanan mengungkap informasi sejarah Islam, silsilah keluarga sultan, dan adat.Untuk kebutuhan pengajaran agama, ulama-ulama Jambi sengaja menulis dan menyalin manuskrip.Manuskripmanuskrip tersebut harus dikonservasi dan dikaji untuk mengungkap sejarah dan dinamika masyarakat Islam di Jambi.Berdasarkan tahun penulisan maupun penyalinannya, manuskrip-manuskrip keislaman ditulis pada masa kesultanan.Besar kemungkinan, ulama-ulama tersebut adalah ulama juga ulama kesultanan (qadhy).

\section{REFERENCES}

Azra, Azyumardi. (1994).Jaringan Ulama Timur Tengah dan Kepulauan Nusantara Abad XVII dan XVIII. Bandung: Mizan,

van den Berg,L. W. C., (1894). "Oendang-oendang Djambi” dalam "Rechtsbronnen van Zuid-Sumatra, uitgegeven, vertaald en toegelicht door," BKI, 43,1894.

Bowen,J. R.,(1991).Sumatran Politics and Politics: Gayo History 1900-1989. New Haven \& London: Yale University Press

van Bruinessen, Martin. (1995). "Muslim of the East Indies and the Caliphate Question," Studia Islamika, Vol. 2 (3), 1995

Dirajo, Datuk Sangguno. (1955). Mustika Adat Alam Minangkabau.Djakarta: Kementerian P \& K 
Gallop, Annabel Teh. (2002). "Malay Seal Inscriptions: a Study in Islamic Epigraphy from Southeast Asia," thesis at University of London, 2002, Appendix.

Fathurahman, Oman. (2009)."Penulis dan Penerjemah Ulama Palembang: Menghubungkan Dua Dunia," dalam Henri Chambert-Loir, Sadur: Sejarah Terjemahan di Indonesia dan Malaysia. Jakarta: Kepustakaan Populer Gramedia.

Jones, R., (1979). "Ten Coversion Myths from Indonesia," in Nehemia Levtzion (ed.), Conversion to Islam. New York: Holmes \& Meier Publishers

Kulsum,Nyimas Umi. (2004). "Naskah-naskah Islam Palembang," dalam Achadiati Ikram (ed.), Jati Diri yang Terlupakan: Naskah-naskah Palembang. Jakarta: Yanassa

Kukushkin, Sergei. (2004). "Hikayat Negeri Jambi: the Structure and Sources of a Nineteenth-century Malay Historical Work," Indonesia and the Malay World, Vol. 32, (92), 2004.

Locher-Scholten, Elsbeth. (2004).Sumatran Sultanate and Colonial State: Jambi and Rise of Ducth Imperialism 1830-1907. New York: Cornell Southeast Asia Program.

Mu'id, Fauzan. "Biografi Guru H. Abdul Majid Ghafar (Suatu Kegiatan Studi Tokoh Di Kelurahan Kampung Jelmu Seberang Kota Jambi),” skripsi Fak. Adab IAIN STS Jambi, 2014.

Muzakir, Ali. (2012). "Naskah-naskah Palembang di Jambi," Skriptoria, Vol. 1, (2), 2012

Muzakir, Ali. (2014). "Petunjuk Baru Silsilah Ahmad Khatib Sambas: Tiga Naskah Melayu," Lektur, vol. 2, 2014.

Pudjiastuti, Titik. (2006)."Looking at Palembang Throught its Manuscripts,"Indonesia and the Malay World, Vol. 34, (100), November 2006

Reid, Anthony. (1969). "Sixteenth Century Turkish Influence in Western Indonesia," Journal of Southeast Asian History, Vol. 10,(03), September 1969

Shellabear, W. G.,(1898). “An Account of Some of the Oldest Malay MSS. now extant," Journal of the Straits Branch of the Royal Asiatic Society, No. 31, July, 1898.

Wahyudi (2019). Naskah Muqaddimah Al-Mubtadin (Jakarta: Perpustakaan Nasional Republik Indonesia.

Buku Inventaris Koleksi Filologika Museum Negeri Provinsi Jambi.

Ms., Jawharat al-Tawhid, Koleksi Museum Si Ginjai Jambi

Ms., Mukhtashar, Koleksi Museum Si Ginjai Jambi

Ms., Qurrat al- 'Ayn li Fardh al- 'Ayn, milik ust. Edi, di Arab Melayu

Ms., Qurrat al- 'Ayn li Fardh al-'Ayn, koleksi Museum Si Ginjai Jambi

Ms., Tanbih al-Ghafilin, koleksi tuan guru Abd al-Majid Ghaffar (w. 1984) di Kampung Jelmu.

Ms., "Catatan Harian Keluarga," koleksi tuan guru Abd al-Majid Ghaffar.

Foto copy Ms., "Ini Sajarah Kerajaan Jambi, ” milik Ratu Mas Fatimah Zahra 